\title{
Comparative study of three lactate oxidases from Aerococcus viridans for biosensing applications
}

\author{
Irene Taurino $^{\mathrm{a}, 1}$, Renate Reiss ${ }^{\mathrm{b}, 1}$, Michael Richter ${ }^{\mathrm{b}}$, Michael Fairhead ${ }^{\mathrm{b}}$, Linda Thöny-Meyer ${ }^{\mathrm{b}, *}$, \\ Giovanni De Micheli ${ }^{a}$, Sandro Carrara ${ }^{\mathrm{a}, * *}$ \\ a Laboratory of Integrated Systems, EPFL - École Polytechnique Fédérale de Lausanne, Lausanne, Switzerland \\ ${ }^{\mathrm{b}}$ Laboratory for Biomaterials, EMPA, Swiss Federal Laboratories for Materials Science and Technology, St. Gallen, Switzerland
}

\section{A R T I C L E I N F O}

\section{Article history:}

Received 7 November 2012

Received in revised form 11 January 2013

Accepted 18 January 2013

Available online 26 January 2013

\section{Keywords:}

L-Lactate oxidases from Aerococcus viridans Engineered and commercial enzymes

Multi-walled carbon nanotubes

Enzyme biosensor

\begin{abstract}
A B S T R A C T
A comparison between engineered and commercially available L-lactate oxidases from Aerococcus viridans was conducted for biosensing applications. Enzymes were adsorbed onto the surfaces of graphite electrodes modified with multi-walled carbon nanotubes. Thermostable L-lactate oxidases were cloned with a (i) N-, (ii) a C-terminal His-tag and (iii) a wild-type enzyme. Subsequently to the heterologous expression in Escherichia coli and purification, we determined the kinetic parameters of these enzymes in solution. The kinetics of the wild-type, of the N-terminally His-tagged enzyme and of the commercial L-lactate oxidase from $A$. viridans were studied with a classical Michaelis-Menten as well as with a substrate inhibition model, while the enzyme carrying a C-terminal His-tag showed no activity. The active enzymes were used to fabricate and comparatively investigate multi-walled carbon nanotubes-based biosensors. The enzyme kinetic results were compared with electrochemical studies. By using both spectrophotometric and amperometric techniques, the inhibition phenomenon fits better to the data especially those data related with Lox-His-N. The electrochemical data of the fabricated enzymatic biosensors showed that the N-terminally His-tagged L-lactate oxidase performed best on carboxyl-modified carbon nanotubes. The sensor based on this engineered enzyme showed the highest sensitivity and lowest detection limit in the range of L-lactate concentration 0-1 mM as well as long term stability over one month.
\end{abstract}

C 2013 Elsevier Ltd. All rights reserved.

\section{Introduction}

The development of innovative strategies for the microfabrication of efficient enzyme-based amperometric biosensors is important because of the continuously emerging fields of new applications. Novel biosensing devices which aim for the high performance detection of different natural metabolites are of great relevance [1].

Aside from the inexpensive and easy fabrication, suitable amperometric biosensors have to match important criteria: they should provide high sensitivity (namely a high electrochemical signal as response to the conversion of the analyte), high selectivity (i.e. highly specific conversion of the desired substrate from a complex sample mixture), low detection limits, wide linear ranges of the signal toward a broad concentration range of the analyte, high

\footnotetext{
* Corresponding author. Tel.: +41 05876577 92; fax: +41 0587657788

** Corresponding author. Tel.: +41 02169309 15; fax: +41021 6934225 .

E-mail addresses: linda.thoeny@empa.ch (L. Thöny-Meyer), sandro.carrara@epfl.ch (S. Carrara).

1 These authors contributed equally to this work.
}

long term stability and high reliability within iterative measurements.

For several enzymes their substrate specificity has in many cases proven to be excellent for the sensing of certain metabolites from a complex mixture. Due to their specificity, their action under physiological conditions, the established techniques to engineer and immobilize them and their diversity, oxidoreductases are the catalysts of choice for amperometric biosensor designs.

A number of research reports have focused on the tailoring of biomolecules to be incorporated onto biosensors, as natural enzymes suffer from the lack of sufficient stability and functionality. Greater stability and activity can be achieved by the rational introduction and localization of mutations together with improved methods for immobilization, resulting in biosensors with better performance [2].

In the literature, there are already some examples of proteins designed for biodevices with improved stability [3], sensitivity and selectivity [4]. All these parameters are strongly influenced by the way the enzyme is attached onto the electrode surface. One possibility to control the immobilization of these biomolecules is the introduction of specific amino acid residues that act like "tails" for e.g. site directed immobilization via affinity adsorption, metal 
complex formation or through the introduction of mutations which enable covalent attachment to the surface [5].

Nanostructures have recently received particular attention to incorporate proteins due to the advantage of working at nanoscale dimensions [6]. Among these, multi-walled carbon nanotubes (MWCNTs) have gained great interest. They have excellent conducting properties and are flexible nanomaterials that seem to mimic an "enzyme friendly" environment [7]. Moreover, MWCNTs can be functionalized before enzyme incorporation with different strategies depending on the desired immobilization method and the individual protein [8].

The improvements of the sensing performance is particularly important for the detection of natural biomolecules (e.g. for food [9], pharmaceutical [10], environmental analysis [11], medicine [12]). An important biocompound that is in need of reliable monitoring is L-lactate. Biosensor applications for the determination of L-lactate range from biotechnology (food quality control [13], cell culture monitoring [14]) to monitoring different aspects of human health [15]. Some previous examples for the amperometric biosensing of L-lactate have been described using L-lactate oxidases (FMNdependent) and L-lactate dehydrogenases (NAD ${ }^{+}$-dependent) from various natural sources. However, for the described biosensors polymeric matrices [16], sol-gel immobilization techniques [17], hydrogels or glutaraldehyde were used for enzyme immobilization [15].

One relatively new and promising approach, which has been established for a variety of enzyme based sensors is to immobilize enzymes on MWCNTs without a polymeric matrix or crosslinking agent (e.g. P450s [12], L-lactate oxidase from Pediococcus sp. [14]), a method which has been shown to significantly enhance the electrochemical signal and thus the sensitivity of the biosensor.

To our knowledge, this work describes for the first time a comparative study with different engineered L-lactate oxidases from Aerococcus viridans and the corresponding commercially available enzyme (cLox) to fabricate L-lactate biosensors. The sensors were fabricated by adsorbing the active enzyme onto the surfaces of carboxyl-modified MWCNTs previously deposited non-covalently onto graphite electrodes.

L-Lactate oxidase catalyzes the following reaction (Eq. (1)) [15].

L-lactate $+\mathrm{O}_{2} \stackrel{\text { L-lactate oxidase }}{\rightarrow}$ pyruvate $+\mathrm{H}_{2} \mathrm{O}_{2}$

The generated hydrogen peroxide can be oxidized at an electrode surface by applying a potential of $+650 \mathrm{mV}$ [18] leading to a signal directly proportional to the concentration of L-lactate in the surrounding solution.

$\mathrm{H}_{2} \mathrm{O}_{2} \stackrel{+650}{\rightarrow} \mathrm{mv}_{2} \mathrm{H}^{+}+\mathrm{O}_{2}+2 e^{-}$

To generate an improved L-lactate oxidase for biosensing applications we cloned variants of the known thermostable L-lactate oxidases from $A$. viridans [19] as (i) $\mathrm{N}$-terminal His-tagged carrying enzyme (Lox-His-N), (ii) C-terminally His-tagged enzyme (Lox-HisC) and as a control (iii) wild-type enzyme (Lox). Subsequently to the heterologous expression in Escherichia coli and purification we determined the kinetic parameters of these enzymes in solution. We compared these data with amperometric studies realized by using biosensors fabricated with the same enzyme load. Firstly, we carried out kinetic experiments with electrochemical methods working in the same range of substrate concentrations. The aim was to study the kinetic behavior of the enzymes after immobilization and to compare with results obtained in solution by UV spectrophotometry. Then, we computed the most important sensing parameters for each type of sensor to identify the device with the highest sensitivity, the best long-term-stability and the lowest detection limit. Hence, we determined the enzyme with higher activity after the immobilization on carboxyl-modified MWCNTs.
The research objective was to gain fundamental insight into the performance of L-lactate-sensors by comparing the commercial as well as the recombinant proteins with and without His-tag.

\section{Materials and methods}

\subsection{Bacterial strains and plasmids}

A. viridans DSM 20340 was obtained from the German collection of microorganisms (DSMZ). E. coli JM109 [genotype endA1 recA1, gyrA96, thi, hsdR17, relA1, supE44, $\lambda^{-}, \Delta$ (lac-proAB), $\mathrm{F}^{\prime}$ (lacI ${ }^{q}$, lacZ $\triangle \mathrm{M} 15$, proAB $B^{+}$, traD36)] and the pQE-30 and pQE-70 expression vectors were purchased from Promega (Madison, USA) and Qiagen (Valencia, USA), respectively. The origin of replication in pQE-30 and pQE-70 is ColE1 (pBR322) and transcription of the inserted gene is controlled by the bacteriophage $\mathrm{T} 5$ promoter (recognized by the $E$. coli housekeeping RNA polymerase) and two lac operator sequences conferring inducibility by isopropyl $\beta$-D1-thiogalactopyranoside (IPTG). For efficient repression the host strain JM109 which over-expresses the repressor Lacl was used. E. coli was routinely grown in LB medium at $37^{\circ} \mathrm{C}$ and $180 \mathrm{rpm}$. For plasmid selection $0.1 \mathrm{mg} / \mathrm{ml}$ ampicillin was used.

\subsection{Cloning of the A. viridans L-lactate oxidase gene}

The putative L-lactate oxidase gene of $A$. viridans (NCBI protein_id: ZP_06807595.1) was PCR amplified from genomic DNA.

Lox-His-N was cloned with the forward primer $5^{\prime}$ gcggcatgcaataacaatgacattgaatataatgc-3' (introducing from the vector atgagaggatcgcatcaccatcaccatcacggatccgcatgc which includes a SphI site (underlined), a 6xHis-tag and the start codon for expression of the cloned gene and removing the natural ATG) and the reverse primer $5^{\prime}$-ccgaagcttctagtattcataaccgtatggg- $3^{\prime}$ (introducing a underlined HindIII site after the native stop codon).

The Lox-His-C was cloned using the forward primer $5^{\prime}$ gcggcatgcttaataacaatgacattgaatataatgc-3' (introducing a SphI site around the native start codon and an additional leucine codon after ATG) and reverse primer $5^{\prime}$-ccgagatctgtattcataaccgtatgggttatc- $3^{\prime}$ which carries a unique underlined BglII site (removing the natural stop codon).

A non-tagged version was cloned with the forward primer $5^{\prime}$ gcggcatgcttaataacaatgacattgaatataatgc-3' (introducing a SphI site around the native start codon and an additional leucine codon after ATG) and reverse primer $5^{\prime}$-ccgaagcttctagta ttcataaccgtatggg$3^{\prime}$ (introducing a HindIII site after the native stop codon). PCR was performed with high fidelity Phusion polymerase (New England Biolabs, Ipswich, USA) and appropriately diluted genomic DNA from A. viridans DSM 20340 as template. The 1134 (Lox-His-N), 1133 (Lox-His-C) and $1136 \mathrm{bp}$ (Lox) PCR products were cloned into the SphI and HindIII or SphI and BglII sites present in the multiple cloning site of pQE-30 and pQE-70, respectively, resulting in plasmids pLox-His-N, pLox-His-C and pLox. The in frame cloning of the desired corresponding expression plasmids pLcO-N and pLcO containing the lactate oxidase gene was confirmed by DNA sequencing.

\subsection{Lactate oxidase production}

E. coli JM109 was individually transformed with pLox-His-N, pLox-His-C or pLox for expression and purification of $A$. viridans L-lactate oxidase. The recombinant $E$. coli strain was cultivated in LB medium supplemented with $0.1 \mathrm{mg} / \mathrm{ml}$ ampicillin at $37^{\circ} \mathrm{C}$ and $180 \mathrm{rpm}$. Starting from an isolated colony, an overnight pre-culture was diluted 1:50 into a $500 \mathrm{ml}$ volume in a 21 Erlenmeyer flask. At an optical density of approximately $0.6\left(\Delta \mathrm{OD}_{600}\right)$, L-lactate oxidase expression was induced by adding $1 \mathrm{mM} \mathrm{IPTG}$. At the same time, the 
temperature was decreased to $30^{\circ} \mathrm{C}$. The cells were further incubated for $4 \mathrm{~h}$ at $180 \mathrm{rpm}$. Cells were harvested by centrifugation at $4{ }^{\circ} \mathrm{C}$ for $30 \mathrm{~min}$ at $4495 \times \mathrm{g}$, washed in $20 \mathrm{mM}$ potassium phosphate buffer $\mathrm{pH} 7.0$, centrifuged again and subsequently stored at $-20^{\circ} \mathrm{C}$. For Lox-His-N purification, frozen cells were thawed on ice and resuspended in $20 \mathrm{mM}$ potassium phosphate buffer with $20 \mathrm{mM}$ imidazole buffer $\mathrm{pH} 7.0$ containing $1 \mathrm{mg} / \mathrm{ml}$ lysozyme and protease inhibitor mix (Roche Complete Protease Inhibitor Mix, EDTA-free) and re-frozen at $-80^{\circ} \mathrm{C}$. Cells were thawed, Benzonase ${ }^{\circledR}$ Nuclease (Roche) was added and the suspension incubated for $1 \mathrm{~h}$ at $37^{\circ} \mathrm{C}$ at $120 \mathrm{rpm}$. The suspension was subjected to twelve $10 \mathrm{~s}$ rounds of sonication with a Branson sonicator equipped with a microtip at a setting of $80 \%$. Cellular debris was removed by centrifugation at $4{ }^{\circ} \mathrm{C}$ for $40 \mathrm{~min}$, at $47,000 \times \mathrm{g}$. Purification was performed on an Äkta purifier FPLC system (GE-Healthcare). Recombinant LoxHis-N was loaded onto a $1 \mathrm{ml}$ His-trap affinity chromatography column previously equilibrated with 5 column volumes (cv) water, $5 \mathrm{cv} 20 \mathrm{mM}$ phosphate buffer $\mathrm{pH} 7.0$ with $20 \mathrm{mM}$ imidazole $\mathrm{pH}$ 7.0. Protein was eluted using an imidazole step gradient of $0,0.175$, 0.4 , and $1 \mathrm{M}$ imidazole. $1 \mathrm{ml}$ fractions containing Lox-His-N protein were obtained in the fractions eluted with $400 \mathrm{mM}$ imidazole. Fractions displaying enzyme activity were pooled and concentrated to $2.5 \mathrm{ml}$ with VivaSpin centricons using a $30 \mathrm{kDa}$ cut-off and subsequently desalted using $2.5 \mathrm{ml}$ PD-10 Sephadex columns and stored in $0.1 \mathrm{M}$ potassium phosphate buffer $\mathrm{pH}$ 7.0. Lox purification and cell lysis was realized as described above. Purification was performed on an Äkta purifier FPLC system (GE-Healthcare). Recombinant Lox was loaded onto a $27 \mathrm{ml}$ Q-Sepharose FF anion exchange chromatography column (GE-Healthcare), previously equilibrated with $20 \mathrm{mM}$ potassium phosphate $\mathrm{pH}$ 7.0. Proteins were eluted with a $\mathrm{KCl}$ gradient from 0 to $1 \mathrm{M}$. Fractions displaying L-lactate oxidase activity, as detected using a coupled 2, 2'-azino-bis(3-ethylbenzothiazoline-6-sulphonic acid) (ABTS) oxidation assay, were pooled and concentrated by ultrafiltration using a $30 \mathrm{kDa}$ cut-off. The sample was loaded onto a Superdex 75 column (GE-Healthcare), previously equilibrated with $100 \mathrm{mM}$ potassium phosphate buffer $\mathrm{pH}$ 7.0. Fractions with L-lactate oxidase activity were pooled, concentrated by ultrafiltration and stored at $-20^{\circ} \mathrm{C}$. The purity of the samples was analyzed by SDS-PAGE using a $10 \%$ polyacrylamide gel.

\subsection{Optical assay on the enzyme activity}

Total protein concentration was determined by UV-Vis absorbance measurements with a Nanodrop ND-1000 spectrophotometer using an extinction coefficient of 51,340 1/( M cm). L-Lactate oxidase activity was assayed by quantifying hydrogen peroxide produced from the coupling reaction with horseradish peroxidase (HRP) $(0.05 \mathrm{mg} / \mathrm{ml})$ and $0.5 \mathrm{mM}$ ABTS. Spectrophotometric L-lactate oxidase activity assays were routinely carried out in a 96-well plate at $35^{\circ} \mathrm{C}$ with $40 \mathrm{mM}$ L-lactate in $0.1 \mathrm{M}$ potassium phosphate buffer at $\mathrm{pH} 7$ using a Bio Tek Synergy Mx spectrophotometer and initiated by adding enzyme solution. The assay volume was $200 \mu \mathrm{l}$. Oxidation of ABTS was monitored at $420 \mathrm{~nm}(\epsilon=36,0001 /(\mathrm{M} \mathrm{cm}))$. The temperature optimum was recorded between $20^{\circ} \mathrm{C}$ and $50^{\circ} \mathrm{C}$ by following ABTS oxidation in an assay volume of $3 \mathrm{ml}$ using a magnetically stirred, temperature controlled cuvette device.

Kinetic parameters of purified enzymes were determined in $0.1 \mathrm{M}$ potassium phosphate buffer $\mathrm{pH} 7$ at $35^{\circ} \mathrm{C}$ against L-lactate (100 mM-3.0 $\mu \mathrm{M}, \mathrm{pH} 7$ ). The assay volume was $200 \mu$ l. Enzymatic assays were performed in triplicate. One unit was defined as the amount of enzyme that oxidized $1 \mu \mathrm{mol}$ of substrate per minute.

In this work, we have used a coupled hydrogen peroxide assay. Upon oxidation of L-lactate to pyruvate, hydrogen peroxide is produced by the enzyme as by-product (because electrons are transferred via the FMN cofactor to molecular oxygen, which acts as terminal electron acceptor).

We used horseradish peroxidase (constant amount) to quantify the amount of hydrogen peroxide generated with ABTS (constant amount) as dye substrate, which is detectable at $420 \mathrm{~nm}$.

In summary, L-lactate oxidase activity was determined with purified enzyme by applying a peroxidase-coupled spectrophotometric method, using ABTS and hydrogen peroxide as substrates at $37^{\circ} \mathrm{C}$ in $0.1 \mathrm{M}$ potassium phosphate buffer $\mathrm{pH}$, which was determined to be optimal.

\subsection{Electrode preparation}

Screen-printed electrodes (SPEs) were obtained from DropSens (model DRP-110). The working electrode was graphite with an active area equal to $12.54 \mathrm{~mm}^{2}$. The counter electrode was also graphite and the reference was an $\mathrm{Ag} \mid \mathrm{AgCl}$ electrode. MWCNTs with carboxyl-modification ( $-\mathrm{COOH}$ groups) were purchased as powder (90\% purity) from DropSens (Spain). The MWCNTs had an average diameter of $10 \mathrm{~nm}$ and the length ranged between 1 and $2 \mu \mathrm{m}$. A solution of MWCNTs in chloroform was prepared with a concentration of $1 \mathrm{mg} / \mathrm{ml}$ [12]. Sonication of the samples was carried out to obtain a homogeneous solution. Lithium L-lactate in form of lyophilized powder (Sigma, Switzerland) was dissolved in Milli-Q water. The electrochemical behavior of Lox-His-N (concentration: $0.4 \mathrm{mg} / \mathrm{ml}$; activity: $9 \mathrm{U} / \mathrm{ml}$ ), Lox (concentration: $0.03173 \mathrm{mg} / \mathrm{ml}$; activity: $117 \mathrm{U} / \mathrm{ml}$ ) and cLox from Roche without tags $(10 \mathrm{kU} / 120 \mathrm{mg}$ ) were compared.

$30 \mu \mathrm{l}$ of the MWCNT-chloroform solution were deposited by drop casting ( $5 \mu \mathrm{l}$ portions) onto the working electrode. The chloroform was allowed to evaporate between two subsequent depositions [14]. The enzymes (26 $\mu \mathrm{g}$ of protein) were additionally casted onto the nanostructured working electrode. Each biosensor was washed with Milli-Q water and then rinsed before experiments. Control experiments (MWCNT-SPEs and $\mathrm{H}_{2} \mathrm{O}_{2}$ [20], MWCNT-SPEs and L-lactate [21], enzyme adsorbed on SPEs and L-lactate [21]) confirm that L-lactate electrochemical detection drastically improves by the use of MWCNTs with adsorbed L-lactate oxidase.

\subsection{Electrochemical assay on the enzyme activity}

The electrochemical response was investigated by chronoamperometry at room temperature under aerobic conditions by applying a constant voltage equal to $+650 \mathrm{mV}$. A Versastat 3 potentiostat (Princeton Applied Technologies) was used to record the data. Routinely, the electrodes were dipped into a stirred $0.01 \mathrm{M}$ phosphate buffer solution (PBS) at $\mathrm{pH} 7.4$ with a volume equal to $25 \mathrm{ml}$. The normal concentration of L-lactate was varied by steps of $0.2 \mathrm{mM}$ successively adding $10 \mu \mathrm{l}$ of $0.5 \mathrm{M}$ in the $25 \mathrm{ml}$ of solution. The error related to the final concentration obtained with this type of dilution is neglectable. The time-step depended on the current stabilization. Sensitivity per unit of area was computed from the angular coefficient of the straight line obtained by plotting the steady-state current per electrode area versus the substrate concentration. The mean square root deviation of each steady-state line was taken as the smallest detectable current signal. The limit of detection (LOD) was computed as three times the signal-to-noise ratio according to the expression $\mathrm{LOD}=3 \delta i / \mathrm{S}$. The limit of quantification (LOQ) was computed as ten times the signal-to-noise ratio according to the expression $\mathrm{LOQ}=10 \delta i / \mathrm{S}$. $\delta i$ is the average standard deviation relative to the steady-state current measurements performed for different analyte concentrations [22]. 


\section{Results and discussion}

\subsection{Spectrophotometry study}

Although Lox-His-C expression was detectable by SDS-PAGE analysis, no activity could be detected with the routine assay ( $40 \mathrm{mM}$ L-lactate) and the enzyme was excluded from further studies. The X-ray structure of the enzyme indicates that the C-terminal is in close vicinity to the entrance of the active site and thus an extended C-terminus (His-tag) may be detrimental [23].

Lox-His-N was purified to homogeneity by Ni-affinity chromatography and Lox was purified by anion chromatography followed by size exclusion chromatography. Lox was co-purified (a minor impurity was determined to be elongation factor $\mathrm{G}$, via tryptic digest from the SDS-PAGE and MALDI-TOF by the Functional Genomics Centre Zurich). Both enzymes were eluted as tetramer.

We modeled these engineered enzymes together with cLox by a typical (Michaelis-Menten) and atypical (substrate inhibition) kinetic profile using Igor Pro (Wavemetrics, Lake Oswego, OR, USA) software in order to facilitate a correct estimation of the relevant kinetic parameters. Typical and atypical kinetic data were calculated based on the initial velocities recorded between $30 \mu \mathrm{M}$ and $25 \mathrm{mM}$ of lactate concentration. Kinetics parameters of Lox, LoxHis-N and cLox are shown in Table 1. Lox showed a more than 3-fold higher $V_{\max }$ than Lox-His-N and 20-fold higher $V_{\max }$ than cLox for both the typical as well as the atypical model. On the other hand, Lox-His-N presented the highest $K_{m}$, namely the concentration corresponding to $V_{\max } / 2$, with both the models. It was found that the enzymes were inhibited by L-lactic acid at concentrations above $12.5 \mathrm{mM}$ (Fig. 1(A)-(C)).

\subsection{Electrochemical measurements}

After characterizing the kinetic of the different Lox constructs in solution, studies of their electrochemical behavior when immobilized on MWCNT-SPEs were made. Using Lox, we obtained an electrochemical response only with $50 \%$ of the prepared samples. It is reasonable to think that this result is due to weak interactions Lox-MWCNTs that cause a considerable loss of immobilized enzyme when sensors are tested and also a reduced stability of the biosensors over the time.

The relative sensitivity was equal to $18.9 \pm 4.8 \mu \mathrm{A} /\left(\mathrm{mM} \mathrm{cm}^{2}\right)$, LOD was $110 \pm 15 \mu \mathrm{M}$ and LOQ was $365 \pm 49 \mu \mathrm{M}$. An electrochemical response appeared with all the SPEs prepared by using Lox-His-N and cLox. In the first case, sensitivity, LOD and LOQ were found to be $35.6 \pm 3.1 \mu \mathrm{A} /\left(\mathrm{mM} \mathrm{cm}^{2}\right), 30 \pm 3 \mu \mathrm{M}$ and $99 \pm 10 \mu \mathrm{M}$, respectively. Using the commercial enzyme, sensitivity was $25.6 \pm 3.4 \mu \mathrm{A} /\left(\mathrm{mM} \mathrm{cm}^{2}\right)$, LOD was determined to be $58 \pm 12 \mu \mathrm{M}$ and LOQ was $193 \pm 41 \mu \mathrm{M}$. The linear range was

\section{Table 1}

Kinetic parameters determined for Lox, Lox-His-N and cLox with typical and atypical models computed from spectrophotometric measurements.

\begin{tabular}{lll}
\hline & Michaelis-Menten & Substrate inhibition \\
\hline Lox & $V_{\max }=86.27 \pm 2.27 \mathrm{U} / \mathrm{mg}$ & $V_{\max }=92.07 \pm 2.96 \mathrm{U} / \mathrm{mg}$ \\
& $K_{m}=0.104 \pm 0.015 \mathrm{mM}$ & $K_{m}=0.121 \pm 0.015 \mathrm{mM}$ \\
& $K_{i}=129.82 \pm 51.70 \mathrm{mM}$ \\
Lox-His-N & $V_{\max }=21.81 \pm 1.13 \mathrm{U} / \mathrm{mg}$ & $V_{\max }=27.79 \pm 0.66 \mathrm{U} / \mathrm{mg}$ \\
& $K_{m}=0.180 \pm 0.047 \mathrm{mM}$ & $K_{m}=0.311 \pm 0.022 \mathrm{mM}$ \\
& & $K_{i}=34.26 \pm 3.60 \mathrm{mM}$ \\
cLox & $V_{\max }=3.72 \pm 0.18 \mathrm{U} / \mathrm{mg}$ & $V_{\max }=4.63 \pm 0.11 \mathrm{U} / \mathrm{mg}$ \\
& $K_{m}=0.119 \pm 0.003 \mathrm{mM}$ & $K_{m}=0.198 \pm 0.015 \mathrm{mM}$ \\
& & $K_{i}=34.26 \pm 3.87 \mathrm{mM}$ \\
\hline
\end{tabular}
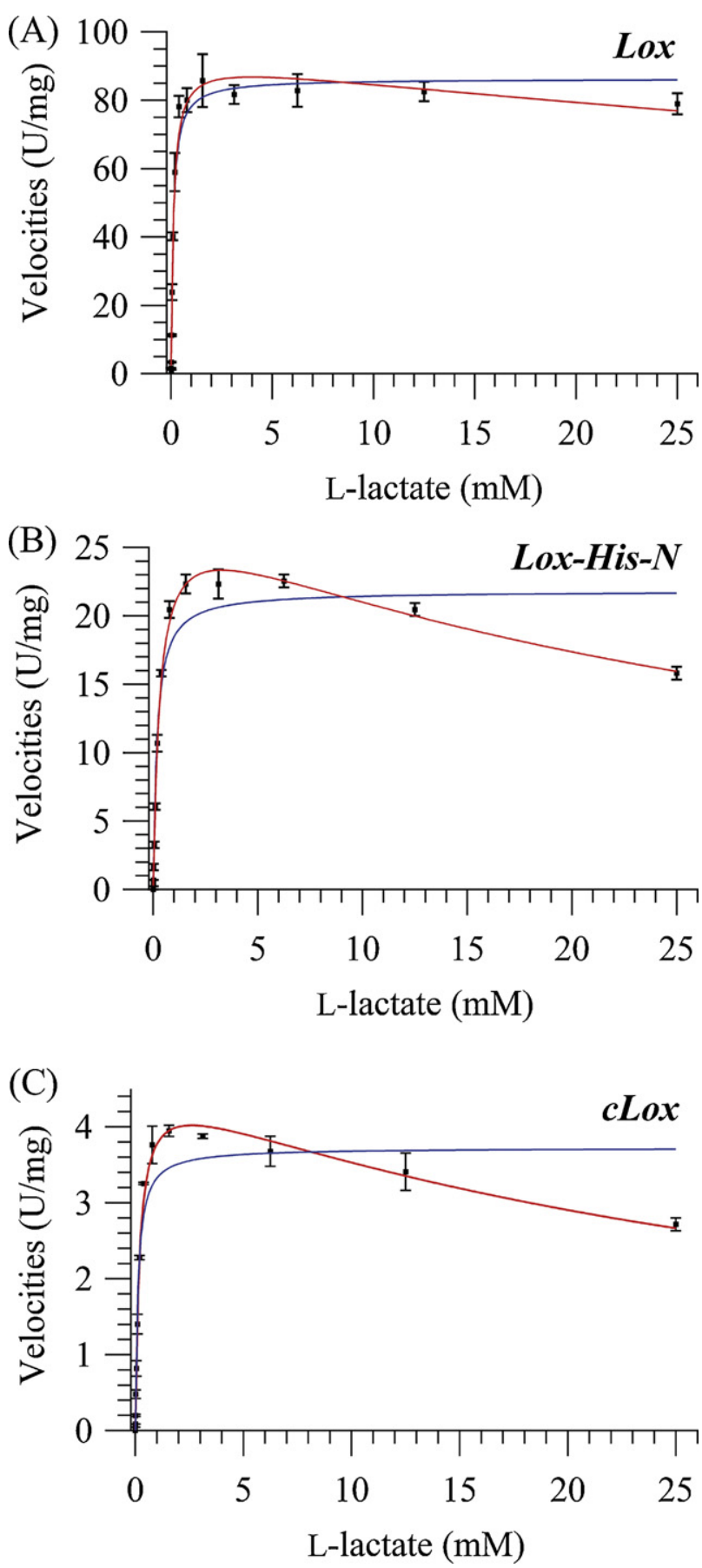

Fig. 1. Kinetic plots obtained with recombinant Lox (A), Lox-His-N (B) and cLox (C) for the acid lactic oxidation via spectrophotometric measurements (coupled enzymatic assay). The specific activity (U/mg) was plotted versus the substrate concentration. Substrate inhibition (red line) and Michaelis-Menten (blue line) equations were used for the data fitting. All data points represent average values with relative standard error (error bars) from triplicate determinations. (For interpretation of the references to color in this figure legend, the reader is referred to the web version of the article.)

0-0.8 mM for Lox-based electrodes and 0-1 mM when Lox-His-N and cLox were used.

After $24 \mathrm{~h}$, subsequent chronoamperometries were performed using only one sample for each type of enzyme-based SPEs. By using Lox-based electrodes, we observed no electrochemical response after three injections of $0.2 \mathrm{mM}$ L-lactate. Moreover, the height of the current steps decreased in repetitive measurements carried out during the same day. With a Lox-His-N-based electrode, 


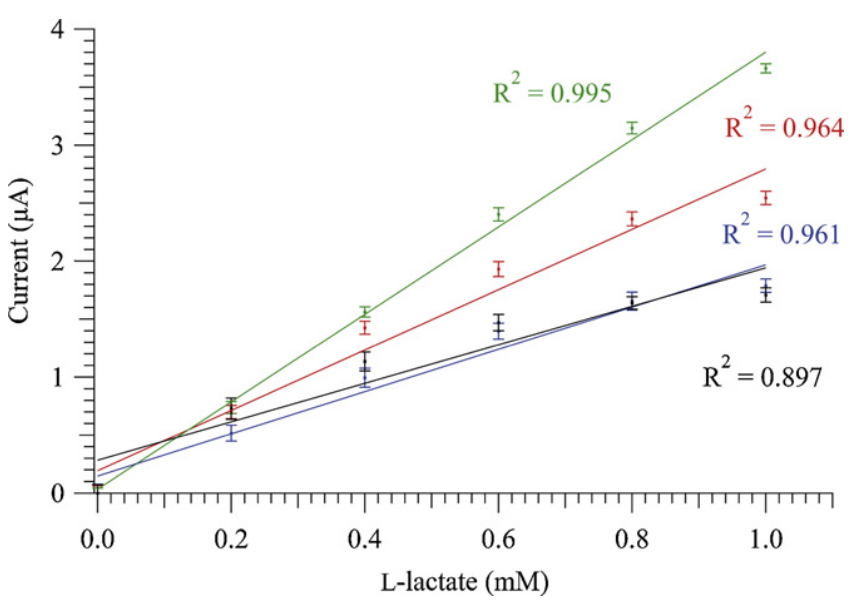

Fig. 2. Decrease of linear range and sensitivity after subsequent measurements (I measurement in black, II in red, III in green and IV in cyan) with SPEs based on cLox. This phenomenon was not observed by using Lox-His-N and Lox. (For interpretation of the references to color in this figure legend, the reader is referred to the web version of the article.)

$24 \mathrm{~h}$ after the preparation we obtained almost the same values for sensitivity, LOD and LOQ $\left(30.1 \pm 3.3 \mu \mathrm{A} /\left(\mathrm{mM} \mathrm{cm}^{2}\right), 42 \pm 3 \mu \mathrm{M}\right.$ and $140 \pm 11 \mu \mathrm{M}$, respectively). The linear range of the sensor remained equal to 0-1 mM. After one day, sensitivity and LOD for SPEs based on cLox were also computed with one device by performing subsequent measurements. We noted a decrease in the linear range and in sensitivity (see Fig. 2).
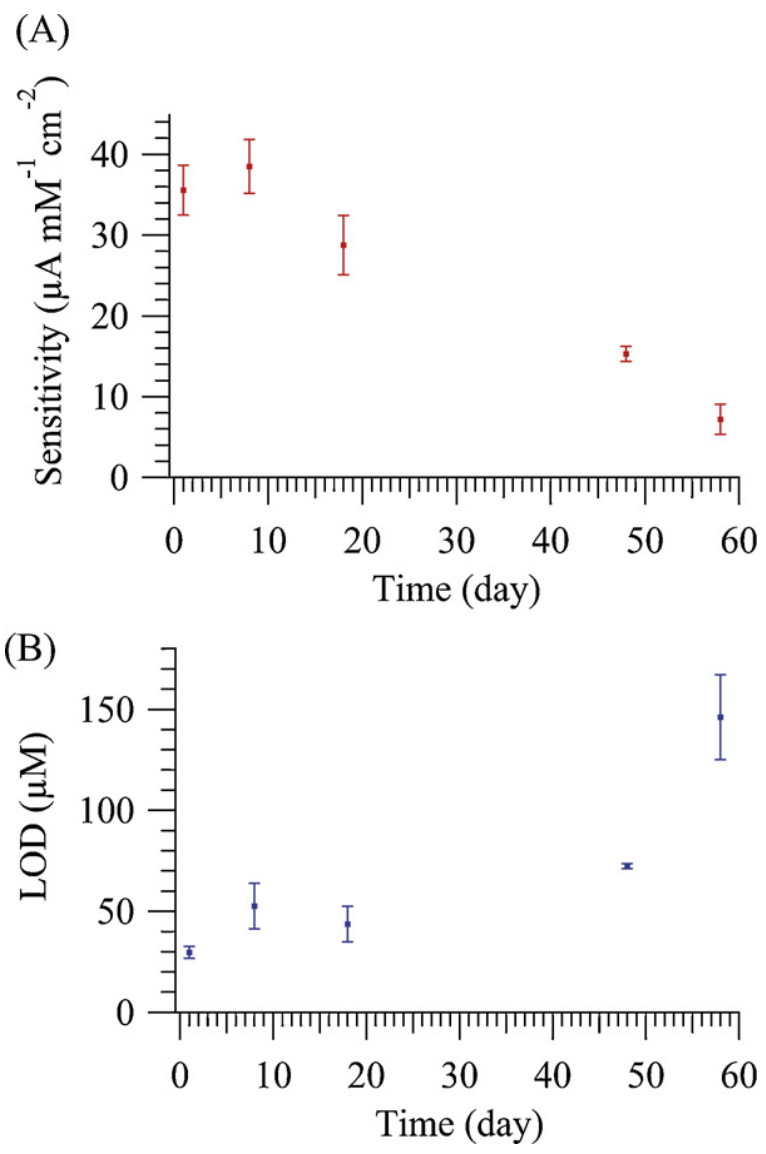

Fig. 3. Sensitivity (A) and LOD (B) of MWCNT-SPEs based on Lox-His-N computed after $1,8,18,48$ and 58 days from the Lox-His-N deposition.
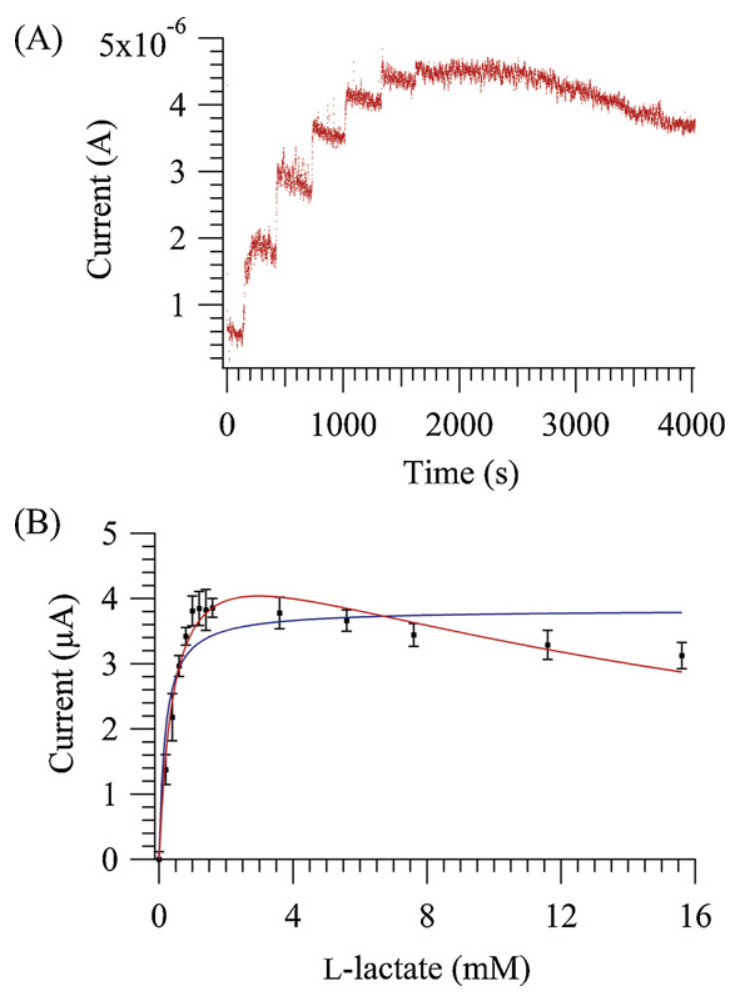

Fig. 4. Chronoamperometry recorded with Lox on successive additions of lactate to a $0.01 \mathrm{M}$ PBS solution $\mathrm{pH} 7.4$ (A) (applied potential: $+650 \mathrm{mV}$ ). Plot of the observed steady-state current versus lactate concentration for Lox. The electrochemical equivalents of the substrate inhibition (red line) and Michaelis-Menten (blue line) equations were used for the fitting of the data (B). (For interpretation of the references to color in this figure legend, the reader is referred to the web version of the article.)

\subsection{Stability study}

We further investigated the long-term stability of the biosensors as this is an important measure of their usefulness in a clinical or commercial setting. After 7 days, at the second injection of the substrate $(0.4 \mathrm{mM})$ into the solution, the current response of SPEs based on Lox did not show an increase. We observed a simultaneous increase of the noise.

However, the sensor based on Lox-His-N showed sensitivity equal to $38.5 \pm 3.3 \mu \mathrm{A} /\left(\mathrm{mM} \mathrm{cm}^{2}\right)$, LOD equal to $53 \pm 11 \mu \mathrm{M}$ and LOQ equal to $176 \pm 38 \mu \mathrm{M} 8$ days after the preparation of the modified electrodes. These findings suggest that this biosensor can be applied as a reusable L-lactate detector within 7 days. Fig. 3(A) and (B) shows the sensitivities and LOD values computed for the prepared electrodes within 60 days after their fabrication. It is worth mentioning that the enzyme remains active up to 50 days after the Lox-His-N deposition.

After immobilization on MWCNTs the Lox-His-N showed higher sensitivity and stability for L-lactate biosensing than Lox and cLox. This is reciprocal when compared to the kinetic data determined in solution (here the Lox had an almost 4 -fold higher specific activity compared to the Lox-His-N). These results are due to conformational changes within the Lox-His-N backbone leading to the exposure of favored binding sites of the enzyme to the nanotubes. Apparently, the 6 histidine residuals favor better binding to the carboxyl MWCNT-modified electrode producing a sensor with improved sensing parameters and stability.

\subsection{Kinetic study by amperometry}

We studied the kinetic behavior of the three enzymes physically adsorbed onto the MWCNT-graphite surfaces by using 

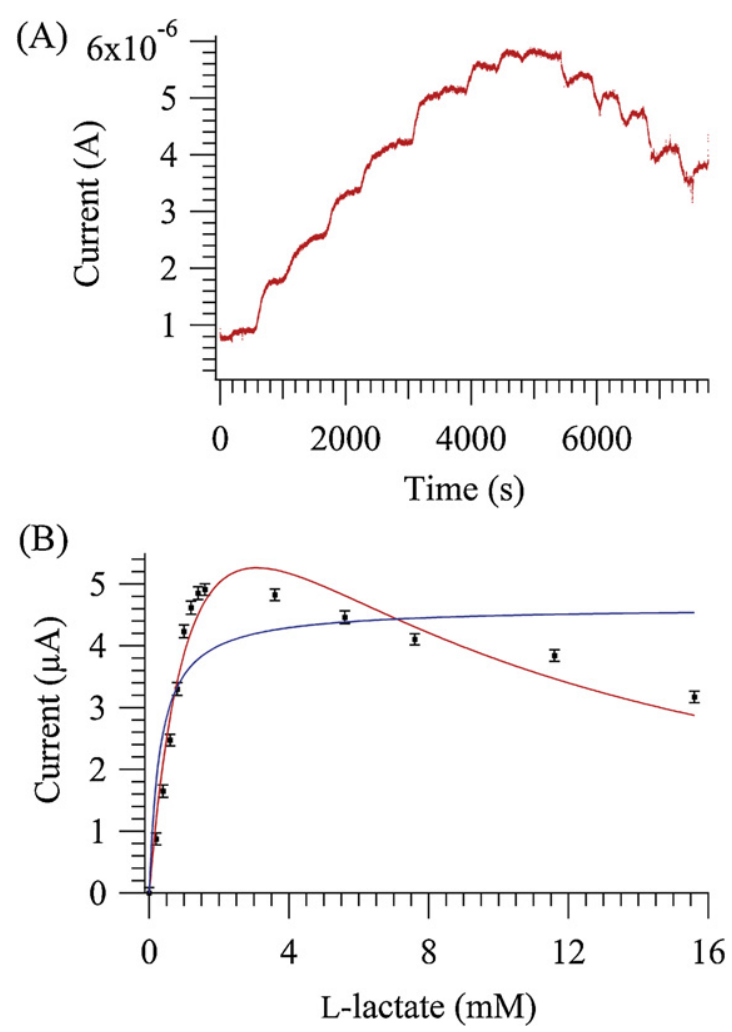

Fig. 5. Chronoamperometry recorded with Lox-His-N on successive additions of lactate to a $0.01 \mathrm{M}$ PBS solution $\mathrm{pH} 7.4$ (A) (applied potential: $+650 \mathrm{mV}$ ). Plot of the observed steady state current versus lactate concentration for Lox-His-N. The electrochemical equivalents of the substrate inhibition (red line) and Michaelis-Menten (blue line) equations were used for the fitting of the data (B). (For interpretation of the references to color in this figure legend, the reader is referred to the web version of the article.)

electrochemical methods. For each enzyme-based sensor we recorded chronoamperometry scans by applying the following protocol:

- 8 injections with $0.2 \mathrm{mM}$ steps (range 0-1.6 mM)

- 3 injections with $2 \mathrm{mM}$ steps (range 1.6-7.6 mM) and

- 2 injections with $4 \mathrm{mM}$ steps (range 7.6-15.6 mM).

Considering the Lox-based sensor, the current saturation started from $1 \mathrm{mM}$ of L-lactate (Fig. 4(A)). A slight current decrease was present for L-lactate concentrations up to $15.6 \mathrm{mM}$. Fig. 5(A) shows the chronoamperometry recorded with a Lox-His-N-based MWCNT-SPE for successive additions of L-lactate into a $0.01 \mathrm{mM}$ PBS solution $\mathrm{pH} 7.4$ going for high substrate concentrations. The "stepped" drop in current starting from $\approx 4 \mathrm{mM}$ of L-lactate is a further evidence for atypical enzyme kinetics. To the best of our knowledge such a clear enzyme substrate inhibition phenomenon has never been demonstrated by amperometry. The electrochemical investigation confirms results obtained with spectrophotometric studies. Indeed, the Lox-based sensor showed a less evident drop in current for high L-lactate concentrations than Lox-His-N also with the amperometric detection (Figs. 1 and 5).

We used both models to fit the electrochemical data acquired with Lox, Lox-His-N and cLox-based sensors.

The electrochemical equivalent of the Michaelis-Menten equation [24] is

$I_{s S}=\frac{I_{\max } \cdot[S]}{K_{m}+[S]}$
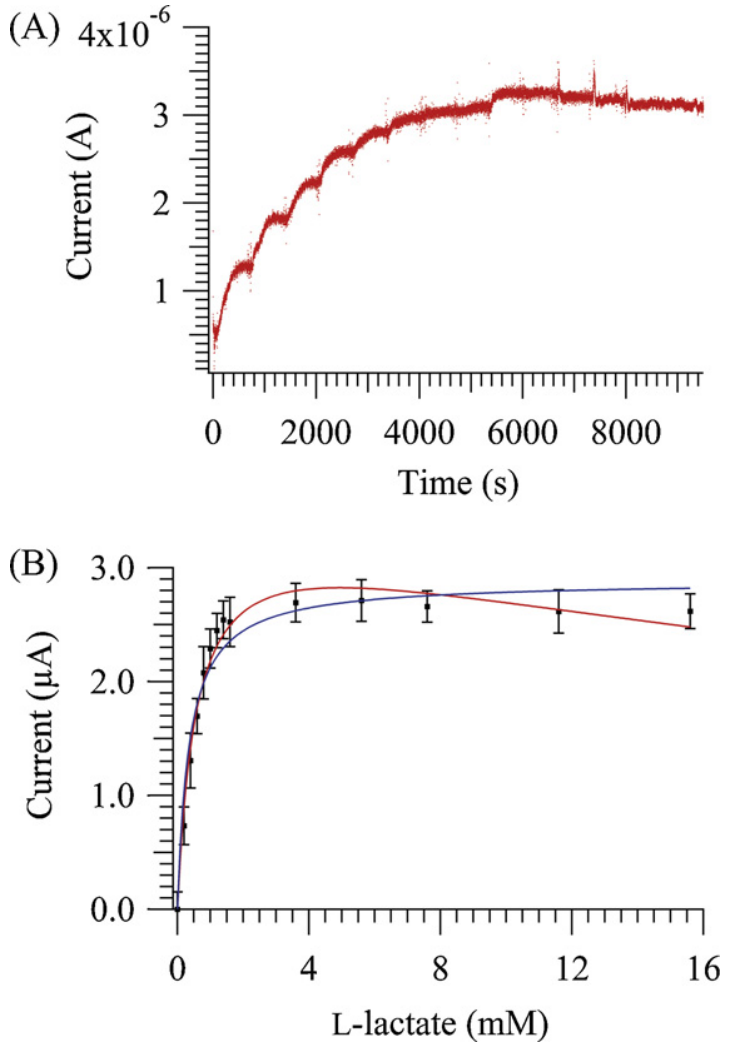

Fig. 6. Chronoamperometry recorded with cLox on successive additions of lactate to a $0.01 \mathrm{M}$ PBS solution pH 7.4 (A) (applied potential: $+650 \mathrm{mV}$ ). Plot of the observed steady state current versus lactate concentration for cLox. The electrochemical equivalents of the substrate inhibition (red line) and Michaelis-Menten (blue line) equations were used for the fitting of the data (B). (For interpretation of the references to color in this figure legend, the reader is referred to the web version of the article.)

where $K_{m}$ indicates of the enzyme kinetics on the biosensor surface, $I_{s S}$ is the steady-state current resulting from the addition of substrate, $I_{\max }$ is the maximum current when the sensor shows saturation by adding analyte to the solution and $[S]$ is the concentration of L-lactate.

The equivalent electrochemical equation for a substrate inhibition phenomenon is

$I_{s S}=\frac{I_{s i_{\max }}}{1+K_{s i_{m}} /[S]+[S] / K_{i}}$

where $K_{s i_{m}}$ and $I_{s i_{\max }}$ have the same meaning of $K_{m}$ and $I_{\max }$ and $K_{i}$ is the inhibition constant.

In reference to the Lox-SPE (see Fig. $4(\mathrm{~B})$ ), $K_{m}$ and $I_{\max }$ were determined by a data fitting based on Eq. (3). The current $I_{\max }$ was calculated to be $3.83 \pm 0.21 \mu \mathrm{A}$. We also computed the substrate concentration corresponding to half of the maximum current $K_{m}$. It was equal to $0.183 \pm 0.066 \mathrm{mM}$. A slightly better fit was obtained by using Eq. (4) in accordance with the spectrophotometric study. We obtained $0.457 \pm 0.087 \mathrm{mM}, 5.28 \pm 0.36 \mu \mathrm{A}$ and $19.27 \pm 4.42 \mathrm{mM}$ as values for $K_{s i_{m}}, I_{s i_{\max }}$ and $K_{i}$, respectively.

In case of Lox-His-N (see Fig. 5(B)), the obtained $K_{s i_{m}}, I_{s i_{\text {max }}}$ and $K_{i}$ were equal to $1.60 \pm 0.57 \mathrm{mM}, 10.73 \pm 2.36 \mu \mathrm{A}$ and $5.93 \pm 2.26 \mathrm{mM}$, respectively. By fitting these data using Eq. (3), we underestimated $K_{m}, I_{\max }$ more than in the case of spectrophotometric results, and they resulted in values of $0.312 \pm 0.149 \mathrm{mM}$ and $4.63 \pm 0.43 \mu \mathrm{A}$, respectively.

Finally, with the cLox-based sensor we determined $K_{m}$ and $I_{\max }$ that resulted in values of $2.88 \pm 0.10 \mu \mathrm{A}$ and $0.358 \pm 0.058 \mathrm{mM}$, respectively (Fig. 6(B)). Based on Eq. (4), $K_{s i_{m}}, I_{s i_{\max }}$ and $K_{i}$ were 
Table 2

Kinetic parameters determined for Lox, Lox-His-N and cLox with typical and atypical models computed from electrochemical measurements.

\begin{tabular}{lll}
\hline & Michaelis-Menten & Substrate inhibition \\
\hline Lox & $I_{\max }=3.83 \pm 0.21 \mu \mathrm{A}$ & $I_{\text {simax }}=5.28 \pm 0.36 \mu \mathrm{A}$ \\
& $K_{m}=0.183 \pm 0.066 \mathrm{mM}$ & $K_{\text {sim }}=0.457 \pm 0.087 \mathrm{mM}$ \\
& & $K_{i}=19.27 \pm 4.42 \mathrm{mM}$ \\
Lox-His-N & $I_{\max }=4.63 \pm 0.43 \mu \mathrm{A}$ & $I_{\text {simax }}=10.73 \pm 2.36 \mu \mathrm{A}$ \\
& $K_{m}=0.312 \pm 0.149 \mathrm{mM}$ & $K_{\text {sim }}=1.60 \pm 0.57 \mathrm{mM}$ \\
& & $K_{i}=5.93 \pm 2.26 \mathrm{mM}$ \\
cLox & $I_{\max }=2.88 \pm 0.10 \mu \mathrm{A}$ & $I_{\text {simax }}=3.48 \pm 0.20 \mu \mathrm{A}$ \\
& $K_{m}=0.358 \pm 0.058 \mathrm{mM}$ & $K_{s i m}=0.572 \pm 0.086 \mathrm{mM}$ \\
& & $K_{i}=42.60 \pm 12.80 \mathrm{mM}$ \\
\hline
\end{tabular}

$0.572 \pm 0.086 \mathrm{mM}, 3.48 \pm 0.20 \mu \mathrm{A}$ and $42.60 \pm 12.80 \mathrm{mM}$, respectively. Kinetics parameters of Lox, Lox-His-N and cLox and computed by using electrochemical data are shown in Table 2.

Lox-His-N had the highest Michaelis-Menten constant in both the models. Therefore, substrate saturation regarding this enzyme is reached at higher substrate concentrations than with the other two enzymes. As a consequence, Lox-His-N offers a larger linear range when used for sensing purposes. These results are in exact agreement with spectrophotometry studies. By using both techniques, Lox-His-N also showed a lower value of the inhibition constant $K_{i}$ indicating a more important substrate inhibition phenomenon.

\section{Conclusions}

In this study we compared three different variants of L-lactate oxidases from $A$. viridans: a commercial non-tagged enzyme and two engineered L-lactate oxidases, namely a N-terminal His-tag variant and the wild-type variant, expressed in E. coli. The two engineered enzymes and the commercial one were separately immobilized onto MWCNT-graphite-based electrodes by physical adsorption.

The immobilized enzymes were employed to fabricate L-lactate biosensors. Kinetic parameters of the enzymes in solution as measured by spectrophotometry showed that Lox has a higher $V_{\max }$ than Lox-His-N and cLox for both the typical and the atypical model. It was noted that, as the concentration of the substrate is increased, the reaction rate eventually begins to decrease from the obtained maximum. It is believed to be due to simultaneous binding of multiple substrate molecules within the enzyme active site, which either results in conformational changes in the enzyme thus reducing the binding capacity or in steric hindrance of substrate molecules reaching the binding site [25]. Inhibition phenomenon fits better to the data related with Lox-His-N also proven by the kinetics study obtained from the electrochemical data (lower $K_{i}$ value). Both the spectrophotometric and amperometric data for Lox-His-N give the highest Michaelis-Menten constant computed by using both the typical and atypical model. Therefore, this enzyme offers a larger linear range when used for sensing purposes.

The apparent activity of Lox and Lox-His-N was reciprocal by using the two investigation techniques of the present study. Polyhistidine-modified enzymes have mostly been attached to CNTs via coordinative bonds [26]. In this work we showed that a His-tagged L-lactate oxidase from $A$. viridans that was physically adsorbed onto the carboxyl-modified MWCNTs can be used for improved biosensing of L-lactate when compared to its wild-type counterpart. The phenomenon of enhanced binding of His-tagged proteins to hydrophobic surfaces was described for binding of His-tagged proteins to tissue culture polystyrene (TCPS) Petri dishes. Furthermore, it has been reported that L-histidine and L-tryptophane rich peptides bind to CNTs [27]. In this work we used an
His-tagged lactate oxidase from $A$. viridans for sensing purposes and the protein-substrate link was realized by adsorption. We proved that a His-tagged L-lactate oxidase from $A$. viridans physically adsorbed onto the carboxyl-modified MWCNTs improves biosensing of L-lactate when compared to the wild-type oxidase. Interestingly, the Lox-His-N-based device showed the highest sensing performance for low lactate concentrations compared with the other two types of L-lactate oxidase from A. viridans. With our study the Lox-His-N sensor showed the highest sensitivity and the lowest detection limit equal to $35.6 \pm 3.1 \mu \mathrm{A} /\left(\mathrm{mM} \mathrm{cm}^{2}\right)$ and $30 \pm 3 \mu \mathrm{M}$, respectively. These parameters are comparable to the most sensitive sensors reported in the literature [15]. Moreover, Lox-His-N retained moderate to good activity up to 50 days after the deposition (LOD from $30 \pm 3 \mu \mathrm{M}$ to $72 \pm 1 \mu \mathrm{M}$ ). The introduction of a simple $\mathrm{N}$-terminal His-tag may preserve the enzyme activity and stability once it is immobilized onto carboxyl-modified MWCNTs. The other enzymes studied in this work did not show this excellent stability and sensitivity.

Due to the inhibition phenomenon, particularly evident with Lox-His-N-sensors, we can divide the calibration curves of our sensors in two parts (Fig. 5(B) to see as example). For low L-lactate concentrations, the current increases linearly with the analyte concentration. Above a certain substrate concentration, values of currents start to decrease when L-lactate is added into the solution. A direct consequence of this result is that one value of current corresponds to two concentrations. The solution of the problem could be the use of a reference sensor having one outer membrane. The membrane, acting as an outer layer diffusion barrier, would enlarge the linear range giving the possibility to know the true value of concentration in solution even with a lower precision (lower sensitivity, larger LOD) [28]. Then, a more accurate determination of the substrate concentration could be carried out by using the membrane-free sensor.

In summary, the $\mathrm{N}$-terminal His-tagged L-lactate oxidase showed higher activity/detection performance after the immobilization onto the MWCNTs-graphite biosensor providing an ideal basis for further improvement of next generation L-lactate sensors. We demonstrated the potential to develop new engineered enzymes with superior properties for fabricating more selective and more robust sensing devices. Additionally, this work gives the first experimental proof of the substrate inhibition for L-lactate oxidases from $A$. viridans adsorbed onto MWCNT-based electrodes by an electroanalytical technique.

\section{Acknowledgements}

The authors would like to thank Thomas Ramsauer for the contribution to the protein engineering side of the present work. This project was evaluated by the Swiss National Science Foundation and financed by the Swiss Confederation with funding via NanoTera.ch.

\section{References}

[1] R. Monošík, M. Stredanský, E. Šturdík, Application of electrochemical biosensors in clinical diagnosis, Journal of Clinical Laboratory Analysis 26 (1) (2012) 22.

[2] C. Mateo, J.M. Palomo, G. Fernandez-Lorente, J.M. Guisan, R. FernandezLafuente, Improvement of enzyme activity, stability and selectivity via immobilization techniques, Enzyme and Microbial Technology 40 (6) (2007) 1451.

[3] K. Sode, T. Ootera, M. Shirahane, A.B. Witarto, S. Igarashi, H. Yoshida, Increasing the thermal stability of the water-soluble pyrroloquinoline quinone glucose dehydrogenase by single amino acid replacement, Enzyme and Microbial Technology 26 (7) (2000) 491.

[4] S. Sotiropoulou, D. Fournier, N.A. Chaniotakis, Genetically engineered acetylcholinesterase-based biosensor for attomolar detection of dichlorvos, Biosensors and Bioelectronics 20 (11) (2005) 2347. 
[5] K. Hernandez, R. Fernandez-Lafuente, Control of protein immobilization: coupling immobilization and site-directed mutagenesis to improve biocatalyst or biosensor performance, Enzyme and Microbial Technology 48 (2) (2011) 107.

[6] S.E. McNeil, Nanotechnology for the biologist, Journal of Leukocyte Biology 78 (3) (2005) 585.

[7] W. Feng, P. Ji, Enzymes immobilized on carbon nanotubes, Biotechnology Advances 6 (2011) 889.

[8] Y.M. Lee, O.Y. Kwon, Y.J. Yoon, K. Ryu, Immobilization of horseradish peroxidase on multi-wall carbon nanotubes and its electrochemical properties, Biotechnology Letters 28 (1) (2006) 39.

[9] S. Milardović, Z. Grabarić, B.S. Grabarić, Sensitive amperometric oxalate biosensor for food analysis, Food Technology and Biotechnology 38 (3) (2000) 203.

[10] L. Campanella, R. Roversi, M.P. Sammartino, M. Tomassetti, Hydrogen peroxide determination in pharmaceutical formulations and cosmetics using a new catalase biosensor, Journal of Pharmaceutical and Biomedical Analysis 18 (1) (1998) 105.

[11] J.H. Lee, R.J. Mitchell, B.C. Kim, D.C. Cullen, M.B. Gu, A cell array biosensor for environmental toxicity analysis, Biosensors and Bioelectronics 21 (3) (2005) 500.

[12] S. Carrara, V.V. Shumyantseva, A.I. Archakov, B. Samorì, Screen-printed electrodes based on carbon nanotubes and cytochrome P450scc for highly sensitive cholesterol biosensors, Biosensors and Bioelectronics 24 (1) (2008) 148.

[13] L.V.Shkotova, T.B. Goriushkina, C. Tran-Minh, J.M. Chovelon, A.P. Soldatkin, S.V. Dzyadevych, Amperometric biosensor for lactate analysis in wine and must during fermentation, Materials Science and Engineering C 28 (5-6) (2008) 943.

[14] C. Boero, S. Carrara, G. Vecchio, L. Calza, G. Micheli, Highly sensitive carbon nanotube-based sensing for lactate and glucose monitoring in cell culture, IEEE Transactions on NanoBioscience 10 (1) (2011) 59.

[15] N. Nikolaus, B. Strehlitz, Amperometric lactate biosensors and their application in (sports) medicine, for life quality and wellbeing, Microchimica Acta 160 (2008) 15.

[16] M.R. Romero, F. Garay, A.M. Baruzzi, Design and optimization of a lactate amperometric biosensor based on lactate oxidase cross-linked with polymeric matrixes, Sensors and Actuators B: Chemical 131 (2) (2008) 590.

[17] J. Huang, J. Li, Y. Yang, X. Wang, B. Wu, J.i. Anzai, T. Osa, O. Chen, Development of an amperometric L-lactate biosensor based on L-lactate oxidase immobilized through silica sol-gel film on multi-walled carbon nanotubes/platinum nanoparticle modified glassy carbon electrode, Materials Science and Engineering C 29 (7) (2008) 1070.

[18] J. Huang, Z. Song, J. Li, Y. Yang, H. Shi, B. Wu, J. Anzai, T. Osa, Q. Chen, A highlysensitive L-lactate biosensor based on sol-gel film combined with multi-walled carbon nanotubes (MWCNTs) modified electrode, Materials Science and Engineering C 27 (1) (2007) 29.

[19] K. Maeda-Yorita, K. Aki, H. Sagai, H. Misaki, V. Massey, L-Lactate oxidase and L-lactate monooxygenase: mechanistic variations on a common structural theme, Biochimie 77 (7-8) (1995) 631.

[20] C. Boero, S. Carrara, G. De Micheli, Sensitivity enhancement by carbon nanotubes: applications to stem cell cultures monitoring, in: Research in Microelectronics and Electronics 2009, PRIME 2009, Ph.D., IEEE, 2009, p. 72.

[21] C. Boero, S. Carrara, G. De Micheli, Design and optimization of a lactate amperometric biosensor based on lactate oxidase and multi walled-carbon nanotubes, in: Nanotech, Montreux, November, 2008.

[22] J. Mocak, A.M. Bond, S. Mitchell, G. Scollary, A statistical overview of standard (IUPAC and ACS) and new procedures for determining the limits of detection and quantification: application to voltammetric and stripping techniques, Pure and Applied Chemistry 69 (2) (1997) 297.

[23] Y. Umena, K. Yorita, T. Matsuoka, A. Kita, K. Fukui, Y. Morimoto, The crystal structure of L-lactate oxidase from Aerococcus viridans at $2.1 \AA$ resolution reveals the mechanism of strict substrate recognition, Biochemical and Biophysical Research Communications 350 (2) (2006) 249.

[24] J.M. Zen, Y.Y. Lai, G. Ilangovan, A.S. Kumar, Electrocatalytic oxidation of hypoxanthine on a nafion/lead-ruthenium oxide pyrochlore modified electrode, Electroanalysis 12 (4) (2000) 280.

[25] T.S. Tracy, M.A. Hummel, Modeling kinetic data from in vitro drug metabolism enzyme experiments, Drug Metabolism Reviews 6 (2) (2004) 231.

[26] M. Holmberg, T.S. Hansen, J.U. Lind, G.M. Hjortø, Increased adsorption of histidine-tagged proteins onto tissue culture polystyrene, Colloids and Surfaces B: Biointerfaces 286 (92) (2011).

[27] S. Wang, E.S. Humphreys, S.Y. Chung, D.F. Delduco, S.R. Lustig, H. Wang, K.N Parker, N.W. Rizzo, S. Subramoney, Y.M. Chiang, et al., Peptides with selective affinity for carbon nanotubes, Nature Materials 2 (3) (2003) 196.

[28] D.R. Thévenot, K. Toth, R.A. Durst, G.S. Wilson, Electrochemical biosensors: recommended definitions and classification, Biosensors and Bioelectronics 16 (1) (2001) 121. 